\title{
Redução da Cânfora
}

\author{
Exemplo de uma transformação selectiva
}

\author{
M. ELISA S. SERRA, D. MURTINHO, J. SEIXAS DE MELO*
}

\section{Estereoquímica: breves considerações}

A quiralidade é um conceito que ultrapassa de longe o âmbito da química. É habitual fazer uso de exemplos do quotidiano para introduzir este tópico. É recorrente a utilização do exemplo das mãos para explicar que uma delas é a imagem não sobreponivel da outra num espelho plano, pelo que se designam por um par de enantiómeros. Também alguns compostos que exibem aromas diferentes podem ter entre eles uma relação de enantiomeria. Por exemplo, a (-)-carvona e a (+)-carvona (Figura 1), responsáveis pelo aroma da menta e dos cominhos, duas plantas utilizadas para condimentar a nossa cozinha, e o (+) -limoneno e o (-)-limoneno, responsáveis pelos aromas da laranja e do limão, respectivamente, são exemplos de enantiómeros. ${ }^{1,2}$ Estes enantiómeros possuem as mesmas propriedades físicas, mas interagem de forma diferente com alguns elementos quirais, como os receptores de sabor e cheiro.

O conceito de quiralidade remonta ao século XIX quando Pasteur separou os enantiómeros do tartarato de sódio e amónio. Estes posssuiam cristais de estrutura hemiédrica - isto é, com formas enantioméricas - permitindo a sua separação manual.

\section{Estereoquímica: alguns conceitos básicos}

Designam-se por estereoisómeros os isómeros que, possuindo igual ordenação dos átomos e respectivas ligações, têm diferenças na respectiva orientação espacial. Existem diversos tipos de estereoisómeros, nomeadamente enantiómeros e diastereoisómeros. Quando duas moléculas são imagem no espelho não sobreponíveis, designam-se por par de enantiómeros. Diastereoisómeros, por sua vez, são estereoisómeros em que nấo se verifica a relação objecto-imagem no espelho. Podem resultar, por exemplo, da existência de mais do que um centro quiral. Se uma molécula possuir $n$ centros quirais pode apresentar um máximo de $2^{n}$ estereoisómeros, alguns dos quais são enantiómeros e outros diastereoisómeros por não possuírem a relação molécula-imagem no espelho não sobreponível. Outro exemplo de diastereoisomeria é a isomeria cis/trans. Uma mistura em partes iguais de dois enantiómeros é uma mistura racémica (ou racemato)

Os diastereoisómeros possuem propriedades físicas e químicas distintas. Já os enantiómeros possuem propriedades físicas e químicas idênticas, como já foi referido, excepto quanto à direcção na qual rodam o plano da luz polarizada, a rotação óptica. Enquanto um dos enantiómeros roda a luz polarizada no sentido dos ponteiros do relógio, o outro roda a luz polarizada no sentido contrário ao dos ponteiros do relógio. Por sofrerem interacção com luz polarizada, os enantiómeros são também designados por isómeros ópticos.

A rotação óptica é uma propriedade que depende da concentração da solução, do caminho percorrido pela luz através dessa mesma solução, do comprimento de onda da luz utilizada, da natureza do solvente utilizado e da temperatura, pelo que se utiliza um outro parâmetro, designado por rotação específica, para definir esta propriedade inerente às moléculas com actividade óptica. Este parâmetro $[\alpha]$ é definido pela seguinte equação:

figura 1 Exemplos de endntiómeros com diferentes propriedades

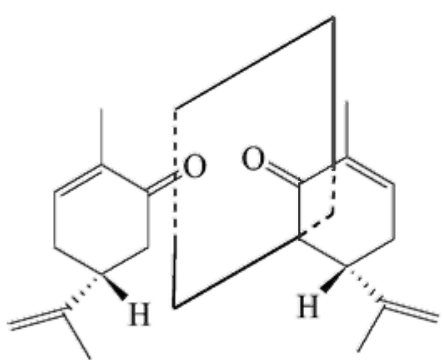

(-)-carvona (+)-carvona

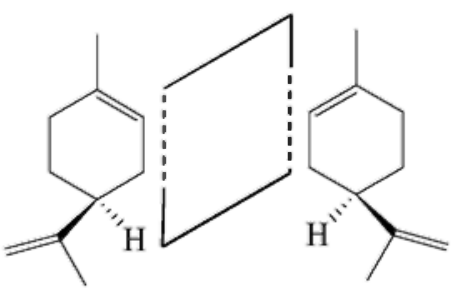

(-)-limoneno

(+)-limoneno

\footnotetext{
*Departamento de Química, Universidade de Coimbra, 3004-535 Coimbra
} 


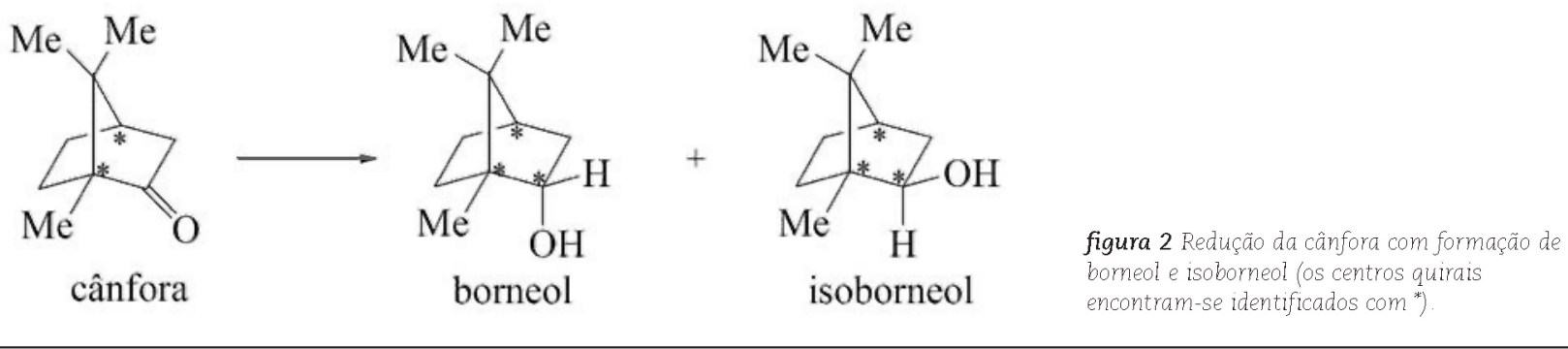

$$
[\alpha]_{\lambda}^{r} \quad \begin{gathered}
\alpha \\
l c
\end{gathered}
$$

em que $T$ é a temperatura medida em ${ }^{\circ} \mathrm{C}, \lambda$ o comprimento de onda da luz utilizada (a risca D do sódio, $\lambda=589 \mathrm{~nm}$, é o mais utilizado), $\alpha$ é o ângulo de rotação medido, / o caminho percorrido pela luz através da solução (dm) e cé a concentração da amostra (g. $\mathrm{ml}^{-1}$ ).

Se, $[\alpha]_{D}^{T}>0$ a luz polarizada roda no sentido dos ponteiros do relógio, o composto diz-se dextrorrotatório. Por outro lado, se, $[\alpha]_{D}^{7}<0$ então a luz polarizada roda no sentido contrário ao dos ponteiros do relógio, e o composto diz-se levorrotatório.

Na presença de catalisadores quirais, a redução de uma cetona proquiral (RCOR') pode ser selectiva originando apenas, ou preferencialmente, um estereoisómero. $\mathrm{Na}$ ausência de catalisadores quirais pode também ocorrer selectividade na redução de cetonas. A formação preferencial de um estereoisómero do álcool pode ser favorecida se na cetona proquiral que sofre redução já existir um centro quiral. Por outro lado, características estruturais da molécula podem igualmente favorecer a selectividade, formando-se preferencialmente um estereoisómero, por exemplo, quan- do a aproximação do agente redutor é favorecida por uma face da molécula. ${ }^{4}$

\section{A cânfora}

A cânfora é um sólido branco cristalino obtido a partir da destilação por arraste de vapor da madeira da canforeira, podendo igualmente ser obtida por via sintética a partir do $\alpha$-pineno. ${ }^{5}$ A estrutura da cânfora foi estabelecida em 1893 por Julius Bredt. ${ }^{6}$ Encontram-se referenciadas diversas aplicações da cânfora, nomeadamente como plastificante de resinas e na medicina como estimulante, inalador e repelente. ${ }^{5} \mathrm{~A}(+)$-cânfora possui um grupo carbonilo que pode ser modificado para dar origem a outros grupos funcionais. Por exemplo, pode ser reduzido para dar origem a álcoois (figura 2). Os álcoois derivados da cânfora, o borneol e isoborneol, possuem propriedades repelentes e antivirais

Da redução da cânfora com boro-hidreto de sódio resulta estereosselectividade, essencialmente devida a questões estruturais. O maior impedimento estereoquímico de uma das faces da molécula, a que possui a ponte metilénica com dois grupos metilo substituintes, condiciona a aproximação do agente redutor por esta face, favorecendo a apro- ximação pela outra, conduzindo assim à formação preferencial de isoborneol (Esquema 1)

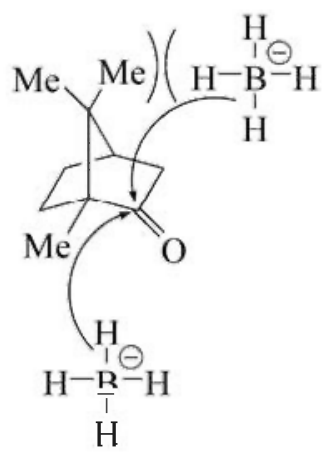

Esquema 1

A percentagem de cada um dos diastereoisómeros formados pode ser determinada por cromatografia gasosa ou ressonância magnética nuclear. A distinção entre os dois compostos so é possive por estes meios serem diastereoisómeros e por isso possuirem propriedades físicas diferentes. Neste trabalho propõe-se a utilização da rotação específica da mistura como via alternativa de determinar a percentagem de cada um dos produtos de reacção. É, assim, possível tirar conclusões sobre a selectividade da redução.

figura 3 Cromatograma onde é possivel identificar como claramente maioritános o reagente e os dois produtos diastereoisoméricos (ver texto). Os restantes picos são devidos ao solvente e a pequenas impurezas.

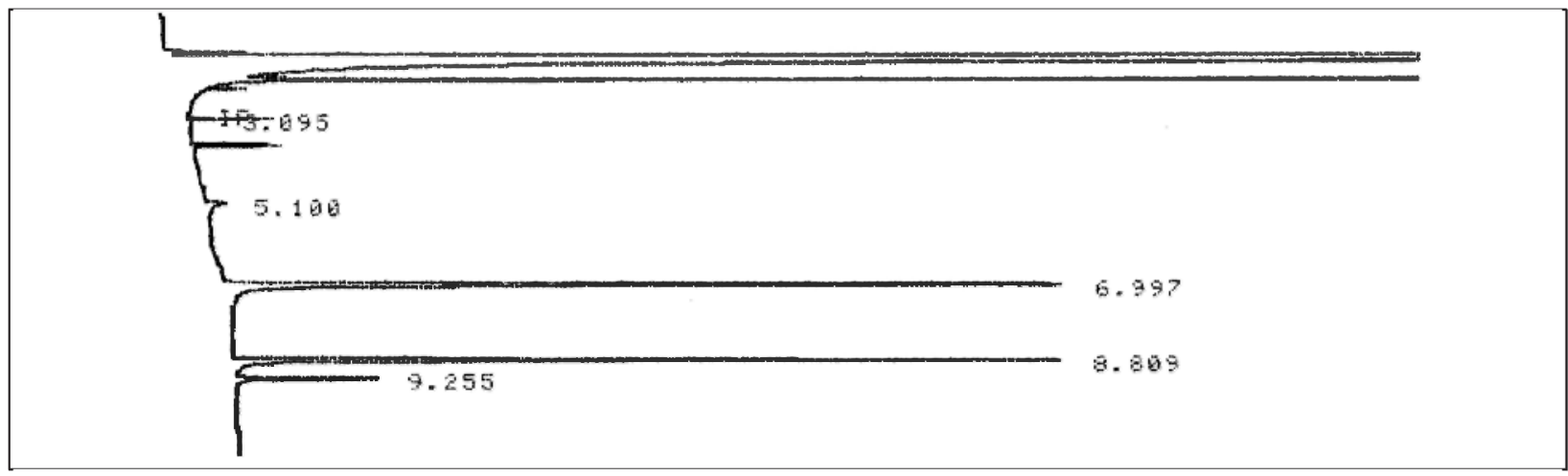


Tabela 1. Valores de rotação específica para a cânfora, borneol e isoborneol. ${ }^{11}$

$[\alpha]_{D}^{\top}$
(+)-cânfora
$+44,3$ (c5, etanol)
(+)-borneo
$+37,4$ (c5, etanol)
(-)-isoborneo
$-32,3$ (c5, etanol)

\section{Redução da cânfora}

Dissolver $1 \mathrm{~g}$ de cânfora em $10 \mathrm{ml}$ de etanol. A esta solução adicionar, com agitação e em banho de gelo, $1 \mathrm{~g}$ de boro-hidreto de sódio em pequenas quantidades. Refluxar a mistura de reacção durante cerca de $30 \mathrm{~min}$. Após este tempo, verter a mistura para um copo com $15 \mathrm{~g}$ de gelo e agitar bem. Precipita um sólido branco que é filtrado e seco. O produto, uma mistura de borneol e isoborneol, pode ser purificado através de uma sublimação, que ocorre por aquecimento do produto a temperaturas de 100 a $130^{\circ} \mathrm{C}$.

Utilizando as condições descritas na literatura ${ }^{78}$ para a redução da cânfora (refluxo de 3,3 mmol de cânfora em metanol durante $15 \mathrm{~min}$. com 4,0 mmol de boro-hidreto de sódio) verificou-se que resultava sempre uma reacção incompleta; aumentando a quantidade de agente redutor e o tempo de reacção obteve-se conversão completa do reagente. A principal inovação deste trabalho consiste na utilização dos valores de rotação específica para a determinação das percentagens relativas dos dois diastereoisómeros formados, só possível no caso de conversões completas, i.e., ausência de reagente de partida (cânfora).

A reacção pode ser acompanhada por cromatografia gasosa (CG) utilizando, por exemplo, uma coluna Supelcowax 10 (30 m, 0.25 d. i., $0.25 \mathrm{~mm}$ ) e um programa de aquecimento de $80^{\circ} \mathrm{C} \mathrm{du}$ rante 2 minutos seguida de uma aumento de $10^{\circ} \mathrm{C}$ por minuto até se atingir os $200^{\circ} \mathrm{C}$. Inicialmente distinguem-se três compostos: a cânfora com tempo de retenção 7 minutos, 0 isoborneol com tempo de retençẫo 8,8 minutos e 0 borneol com tempo de retenção $9,3 \mathrm{mi}$ nutos (figura 3). Desde logo se verifica que 0 isoborneol se forma em maior quantidade. A reacçăo encontra-se completa ao fim de 30 minutos, apre- sentando o cromatograma apenas indicação da existência de borneol e isoborneol. Na ausência de CG podem traçar-se espectros de IV. O desaparecimento da banda a 1668-1748 $\mathrm{cm}^{-1}$ (carbonilo da cânfora) $)^{10}$ e o aparecimento da banda a $3338 \mathrm{~cm}^{-1}$ (hidroxilo do borneol e isoborneol) ${ }^{10}$ permite concluir se a reacção foi ou não completa

No caso da cânfora, a distribuição de produtos encontra-se descrita na literatura como sendo $86 \%$ isoborneol e $14 \%$ de borneol. ${ }^{4}$

A análise do cromatograma (figura 3) referente ao trabalho realizado indicou percentagens finais de $83 \%$ e $17 \%$, para o isoborneol e borneol, respectivamente. Os valores estão muito próximos dos apresentados na literatura. É de referir ainda que a percentagem relativa dos dois produtos no decurso da reacção se mantém aproximadamente constante.

A percentagem relativa dos dois diastereoisómeros pode também ser determinada através da medição da rotação óptica da mistura.

Preparando uma soluçăo da mistupa (c5, etanol - $5 \%$ peso/volume) e determinando a rotação específica é possível calcular as percentagens relativas dos dois diastereoisómeros, tendo em consideraçăo as suas rotaçồes específicas.

Os dados apresentados na Tabela 1 dizem respeito às rotações específicas do reagente e produto puros. ${ }^{11}$

Neste trabalho determinou-se a rotação específica (polarímetro Optical Activity AA-5) da mistura, obtendo-se o valor de $=-20$ (c5, etanol).

O seguinte sistema de duas equaçốes a duas incógnitas permite determinar as percentagens de isoborneol e borneol presentes na mistura:

$$
\left\{\begin{array}{c}
x+y=1 \\
-32,3 x+37,4 y=-20
\end{array}\right.
$$

onde $x=$ fracção de isoborneol e $y=$ fracção de borneol.

Da resolução deste sistema obtêm-se os valores de $x=0,824$ para o isoborneole $y=0,176$ para o borneol $(82,4 \%$ e $17,6 \%$, respectivamente). Como se pode constatar, os resultados obtidos por cromatografia gasosa e por polarimetria são concordantes.

Pode concluir-se que a redução da cânfora é uma transformação selectiva e completa nas condições de reacção aqui apresentadas, obtendo-se predominantemente o isoborneol como produto da reacção. As percentagens relativas dos dois diastereoisómeros podem ser determinadas quer por cromatografia gasosa, quer por polarimetria como aqui se sugere, observando-se uma concordância entre os valores obtidos pelos dois métodos.

\section{Notas Finais}

Este trabalho é realizado em disciplinas laboratoriais de Química Orgânica do segundo ano das licenciaturas em Química e Química Industrial, no Departamento de Química da Universidade de Coimbra. O trabalho revela-se interessante e facilmente realizável em qualquer laboratório que possua um cromatógrafo gasoso e/ou um polarímetro.

Referências

(1) Ault, A. J. Chem. Educ. 2002, 79, 572.

(2) Saxon, C.; Brindley, S.; Jervis, N.; Jones, G. R.; Morgan, E. D.; Ramsden, C. A.J. Chem. Educ. 2002, 79, 1214.

(3) Kostyanovsky, R. B. Merideleev Comm 2003, 3, 1.

(4) Brown, H. C.; Muzzio, J. J. Am. Chem Soc. $1966,88,2811$

(5) www.epa.gov. acedido em 2005.

(6) Kauffman, G. B. J. Chem. Educ. 1983, 60, 341.

(7) Markgraf, J. H. J. Chem. Educ. 1967, 44, 36.

(8) http://courses.chem.psu.edu/chem36/ Experiments/Revised $\% 2036 \% 20$ Expts/Expmt 125.pdf

(9) www.aist.go.jp/RIODB/SDBS/menu-e.htm| àcédidò êm 2005.

(10) www.acros.be. acedido em 2005

(11) Dictionary of Organic Compounds; Eyre and Spottiswoode, Ltd.: London, 1953. 